\title{
VIRTUAL CULTURAL LANDSCAPE LABORATORY BASED ON INTERNET GIS TECHNOLOGY
}

\author{
R. Bill \\ Rostock University, Professorship for Geodesy \& Geoinformatics, Germany - \{ralf.bill $\} @$ uni-rostock.de
}

KEY WORDS: Spatial Information science, Interoperability, web-based, cultural landscapes, data infrastructure

\begin{abstract}
:
In recent years the transfer of old documents (books, paintings, maps etc.) from analogue to digital form has gained enormous importance. Numerous interventions are concentrated in the digitalisation of library collections, but also commercial companies like Microsoft or Google try to convert large analogue stocks such as books, paintings, etc. in digital form. Data in digital form can be much easier made accessible to a large user community, especially to the interested scientific community.

The aim of the described research project is to set up a virtual research environment for interdisciplinary research focusing on the landscape of the historical Mecklenburg in the north-east of Germany. Georeferenced old maps from 1786 and 1890 covering complete Mecklenburg should be combined with current geo-information, satellite and aerial imagery to support spatio-temporal research aspects in different scales in space (regional 1:200,000 to local 1:25.000) and time (nearly 250 years in three time steps, the last 30 years also in three time slices).

The Virtual Laboratory for Cultural Landscape Research (VKLandLab) is designed and developed by the Chair of Geodesy and Geoinformatics, hosted at the Computing Centre (ITMZ) and linked to the Digital Library (UB) at Rostock University. VKLandLab includes new developments such as wikis, blogs, data tagging, etc. and proven components already integrated in various data-related infrastructures such as InternetGIS, data repositories and authentication structures. The focus is to build a data-related infrastructure and a work platform that supports students as well as researchers from different disciplines in their research in space and time.
\end{abstract}

\section{MOTIVATION}

Modern knowledge and information society with its various possibilities of efficient communication and easy access to very large amounts of information and powerful computing technology is a new challenge to science. The chances to achieve better scientific results, both qualitatively and quantitatively, with the new methods have increased considerably in parallel, but also the difficulty to control such distributed, dynamic system components. Under the heading "escience" a network-based science, "grid-based science" or "digitally enhanced science" is becoming increasingly established. This requires the systems development and the organizational structures of a network and middleware infrastructure, with which computational resources, information resources, application programs can be offered, requested and allocated for community-specific applications. So-called virtual research environments (VRE) are going to be established.

With the promotion of virtual research environments the German Research Foundation (DFG) aims to further develop integrated information infrastructures for grid-based research. The new communication technologies and publication procedures permanently change the existing information infrastructure and the traditional publication process. Digital information and communication networks provide the technical requirements for time- and location-independent collaboration. Essential for the development and effective use of new communication and publication networks are powerful tools and infrastructures to support the scientific work processes. These include the virtual research environments, platforms for network-based collaborative work processes that support new forms of cooperation and result in an easier access to scientific data and information. They provide both a central access to each subject-specific resource, data and document as well as the necessary conditions for a substantive link between the various information units. A very recent, world-scale study of virtual research environments was published by CARUSI\&REIMER (2010).

\section{CULTURAL LANDSCAPE RESEARCH AND HISTORICAL GIS}

Cultural landscape analysis - as an example of historicalgeographical, land use change and land improvement research requires the modelling of landscape and socio-economic processes over time in their history. In assessing the sustainability of landscape developments the spatial distribution patterns and the mosaic of key elements in the landscape need to be considered. For this purpose, the cultural landscape research uses historical data sets. Large amounts of data collected in electronic form over the last decades and centuries in statistical offices, museums, archives and numerous historical and geographical research projects can be set in value using modern IT methods. For questions of landscape monitoring (NEUBERT \& WALZ, 2002, WALZ ET.AL., 2004) or for inventarisation of the cultural landscape (PLÖGER, 2003) since many years historical maps are investigated with modern information and communication technologies (ICT) methods. The "European Social Science History Association" operates a network of "Historical Computing and GIS." At the international level, it is especially the basic works of KNOWLES, 2008, and GREGORY \& ELL, 2007, which deal with issues of space and time and their treatment in GIS from the perspective of historical geography.

HISGIS Fryslân covers the oldest land register in the Netherlands as a basis for a historical GIS. Presented here are vectorized cadastral maps and plots of the registers in 1812 and 1832. HISGIS serves as a basis for the combination of maps and data layers with the oldest census data, called house number registrations. The resulting cumulative information can be 
presented as thematic maps and used for research in geographical and historical disciplines (MOL \& EKAMPER 2011).

\subsection{Historical maps and geo-information data sets in Mecklenburg}

For over a decade the professorship of Geodesy and Geoinformatics is dealing with the exploitation of historical maps (sometimes also called old maps) in digital form as a source of interdisciplinary landscape research. Around the year 2000 for the first time an attempt started to offer maps on the area of the historic Mecklenburg in a homogeneous digital form. Scanning the old maps of Wiebeking (dated from 17861788 , in total 48 sheets, scale $1: 24.000, \sim 2 \mathrm{~GB}$ of data) and Schmettau (1788, 16 sheets, scale 1:50,000, 2 GB of data) and the topographic base maps (so-called "Preußische Messtischblätter", 1877-1889, 168 sheets, scale 1:25,000, 18 GB of data) made available the oldest topographic maps of large parts of the federal state Mecklenburg-Vorpommern (more precisely, of the duchies of Mecklenburg-Strelitz and Mecklenburg-Schwerin, see Figure 1) in an excellent quality (GROßE/ZINNDORF, 2001, GROßE, 2003).

KREßNER, 2009 evaluated these scanned maps in terms of their quality and their geometric origin. He investigated the thematic suitability for scientific analysis, especially in relation to landscape research issues.

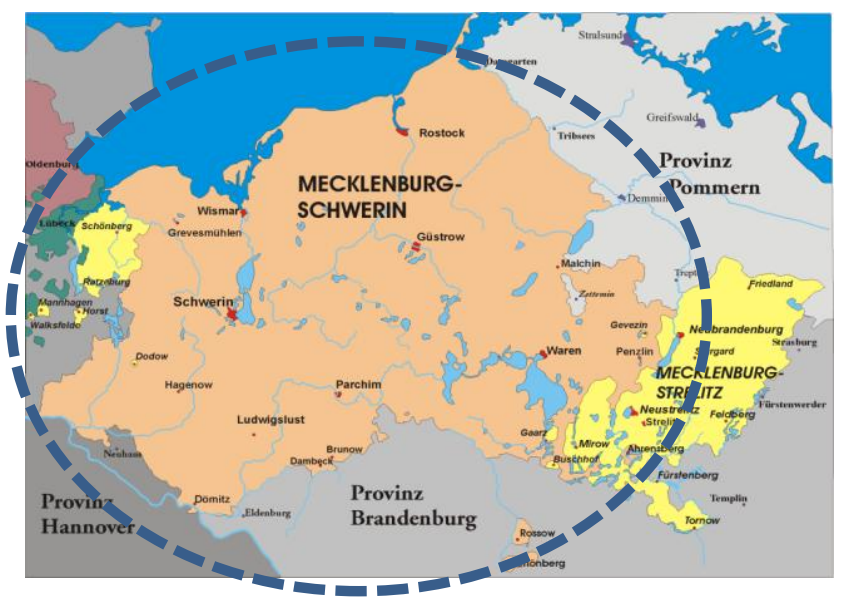

Figure 1. Area coverage of Mecklenburg from 1786 in the today's boundaries of Mecklenburg-Western Pomerania.

These old maps are now geo-referenced and their geometric quality is described. They can be deployed and integrated into GIS in the sense of historical digital primary research data holdings for science. This is the main data set for the designed virtual research environment for the modern cultural landscape research. With a territorial extension of more than $15,000 \mathrm{~km}^{2}$ and a time horizon of around 225 years, there is nothing comparable in the world. Combined with the spatial data of today (digital topographical maps in raster (DTK 10) and vector form (DLM) as well as digital orthophotos from the Authoritative Topographic-Cartographic Information System (ATKIS) in Germany), and embedded in modern ICT, new research avenues and forms of access for cultural landscape research are becoming available. The potential of such a virtual platform for cultural landscape research is illustrated by KREßNER, 2009 with small case studies and student projects on spatial-temporal changes in the region of Ribnitz, a small city in Mecklenburg.
Parallel to our work another activity takes places in the eastern part of Mecklenburg-Western Pomerania. The Swedish land survey of Pomerania between 1692 and 1709 is considered as the first land register in the Holy Roman Empire of German Nation. For an area of approximately $8,700 \mathrm{~km}^{2} 1,600$ handdrawn colored parcel maps and descriptive text of about 65,000 pages have survived. Currently a digital scholarly edition of a major part of the material is being developed (BUSCH ET.AL. 2009).

\section{THE PROJECT VKLANDLAB}

\subsection{Technology partners in the project}

The research project VKLandLab (in German Virtuelles Kulturlandschaftslaboratorium, in English Virtual cultural landscape laboratory) is processed by several partners in common. On the one hand, the underlying technology (see chapter 4) is designed and developed at the chair of Geodesy and Geoinformatics $(G G)$. As infrastructure units the University Computing and Media Centre (ITMZ) and the University Library (UB) are participating.

$I T M Z$ provides network-based central and distributed information and communication services for university research, teaching and administration. Here, various database applications are operated and maintained, including a central image database and the digital library of the University. This ensures a full provision of online documents such as digital research data and results, literature of the library, and online databases.

At the University Library $(U B)$ the Digital Library is developped as a central, important strategic infrastructure component of the university. The document server RosDok (http://rosdok.uni-rostock.de) as part of the digital library - a joint project and cooperative service of the University Library, the ITMZ and the department for databases and information systems of the university - includes all forms of electronic publications to be researched, presented, and permanently archived. RosDok's available documents are accessible by metadata and are free (open-access) on the Internet. Digitised sets of historical documents are also stored and structured according to the METS format, allowing them to be integrated and visualised in the developed viewer. For the exchange of metadata with OAI search engines, the OAI-PMH interface can be used. A conversion to common metadata formats (eg. Dublin Core, XMetaDiss) can be done. To increase the visibility of the documents they are registered in the catalogue of the library and in the catalogue of the Common Library Network in Germany (GBV).

\subsection{Research partners in the project}

The technological platform is evaluated and used by an interdisciplinary team of students and researchers for their research interests. Different scientific disciplines of the University of Rostock are involved:

- Historical sciences interrelate a database for Mecklenburg census of 1819 in the Grand Duchy of Schwerin to Schmettau's maps and a census of 1867 in the Grand Duchy of Schwerin on the first topographic maps of the Prussian land surveying.

- $\quad$ Settlement planners and experts for preservation of monuments dedicate themselves to the investigation of village forms, e.g. parish forms and farmyard types. For the region a canon of typical, representative and satisfactory phenomena (local forms and their stages 
of development) should be derived and prepared for a systematic and appropriate generalization.

- Landscape ecologists, dealing with the analysis of areal distribution, severity and location of the woodland and marshland in Mecklenburg over time, try to edit and create a basis for large-scale analysis of the structure (biodiversity) and function (humus storage) of forests and moor.

- Landscape planners study the implication of the historical-genetic cultural landscape development in the tools of today's spatial planning and management of historic landscape features. The dynamics of land changes is an important basis for defining sustainable models and general principles for spatial planning and regional policy.

- Hydrologists generate hydro-meteorological and hydrological relevant basic parameters for further analysis in the cultural landscape, such as for grass reference evapotranspiration, the climatic water balance, the expansion of drainage systems and water development. This will create the basis for the coupling with model-applications (eg. water and nitrogen balance models).

- Geodesists and geomorphologists investigate the kettle holes, hollow forms (in German called Sölle), caused by melting out of an enclosed sediment block and distributed especially in the younger Pleistocene areas. In Mecklenburg-Pomerania about 90,000 hollow forms occur, nevertheless their form of origin and development is still under discussion.

- The spatial-temporal analysis of the development of habitat fragments, the analysis of the spatial distribution pattern of these kettle holes in their historical development, the floristic inventory of selected hollow forms particularly is of interest to biologists. The comparison with existing historical data and the analysis of the relationship between landscape dynamics (eg reduction in the number of kettle holes) and floristic composition of plant communities in kettle holes may allow to derive longterm preservation strategies of species-rich communities in kettle holes.

\section{CONCEPT AND IMPLEMENTATION}

\subsection{Components of the platform}

Following the basic principles of e-science the technical objectives of the project are to create a central portal application, that support researchers in their collaborative work with essential tools and resources for dealing with spatial data. A central component in addition to components of communication and workflow management is a spatial data infrastructure (SDI), which includes a basic collection of technologies, policies and comprehensive agreements in order to make spatial data consistently available and accessible (BILL, 2010). The Open Geospatial Portal Reference Architecture defines a SDI as a central access point to geographic information resources. One of the intended project objectives is to provide the opportunity to investigate, view, generate and administer content and spatial information for different user groups at one (virtually) central location. The OGC reference architecture is thus a good basis to formulate technical demands on the development and coordination of the portal application. The components of the information system (see Figure 2) can be divided into the following categories:

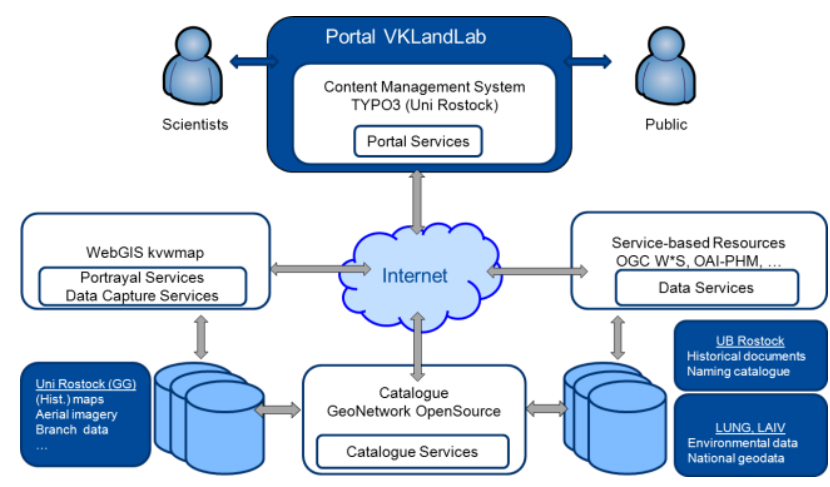

Figure 2. Portal components with related services and data sources.

Portal services provide a central entrance point and access to all relevant functions and tools of the portal application. In addition to the aggregation and abstraction of all available resources, they also allow access to management and administration of the portal itself. To implement this functionality, combined with the design of fixed and variable content of the web site of the project, a free Content Management Framework (TYPO3) is used. In addition to predesigned layouts in the corporate design of the University of Rostock, the flexible PHP framework supports the embedding of dynamic visualization and processing components of the portal application.

Data services and view services allow the provision of spatial data for processing by the users and their visual map-based treatment as a foundation for a detailed assessment of the content. Therefor the open source WebGIS framework kvwmap is used (BILL/KORDUAN/RAHN, 2008). kvwmap is built on top of the UMN MapServer development for collecting, processing, analyzing and presenting geospatial information. The user interface (see Figure 3) of a Web-based client offers similar functionality as desktop GIS for viewing and processing of spatial objects and specialized describing data.

Catalogue services permit the discovery of spatial data based on searchable parameters for the data theme, origin, and appearance. The search in a central meta information directory put users in the position to identify and allocate necessary data and make them accessible independent on type and location of their storage. For this purpose the free web-based application catalogue GeoNetwork OpenSource is used. Portal users can query metadata to existing research records and create own metadata for new records. Metadata records can be presented in various standardized forms. For geospatial information this means the use of ISO 19115/19139 (with any possible INSPIRE compliance).

Furthermore, in the database of the catalogue references are kept to historic documents from the holdings of the University Library. This is achieved through a continuous alignement between GeoNetwork and the catalogue of the library system through the OAI-PHM protocol.

All the above mentioned components are available as standalone applications, but they can also be integrated strongly intertwined with each other because of their consistent and standardized approach to service-based OGC / WWW interfaces. Thus, a higher-level abstraction is achievable for user applications. The modularity of the individual application also enables future flexibility and scalability of the entire portal for sharing and modification of individual components. 


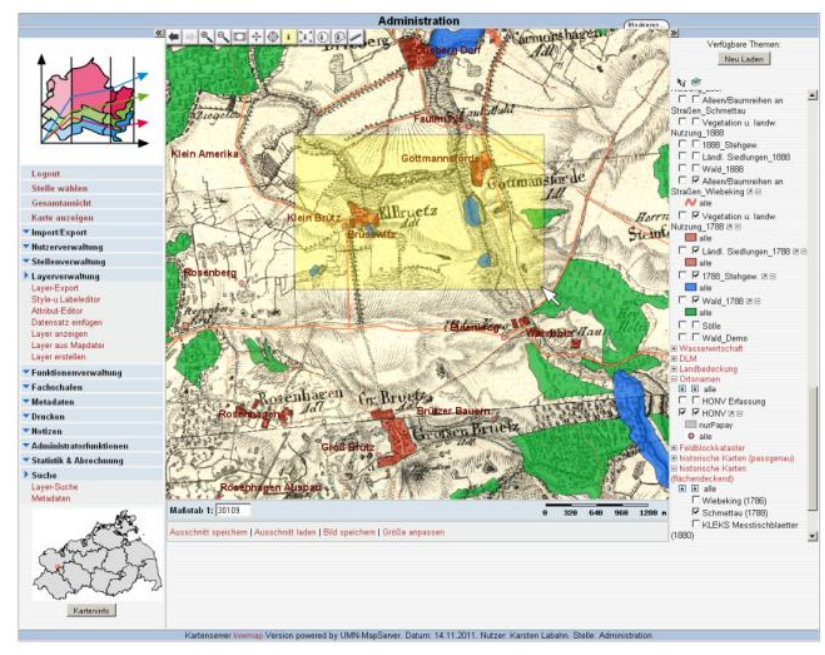

Figure 3. Search query for documents in kvwmap.

At present, another component of the category data services, but here treated separately as a special feature of the historic nature of the portal application listed, is in the design and development phase. This is a historical place names directory. Local references do exist in metadata records of many cultural and historical projects or reference to catalogues of libraries. Nevertheless their existing query mechanisms for place names, both geographically and chronologically, are less suitable for visualization and automated analysis. Within the project a webbased local name service (a gazetteer service) is implemented in compliance with relevant interface standards (Web Feature Service). This service provides a high resolution search in time and space in Mecklenburg for local historical terms and synonyms over the last 250 years. Ambiguities are resolved here in as much detail as possible and links to current/recent official administrative units are produced. The underlying data set is combined from a series of freely available contemporary (such as genealogienetz.de), administrative (State Office of Internal Administration (LAIV) MV, Federal Agency for Cartography and Geodesy (BKG)) as well as historical name inventories (Wossidlo Archive, Historical Census composed from 1819/1867). Due to the resulting spatial referencing it is possible to link records to spatial research services giving users expanded opportunities for access. Furthermore, the automated integration into higher level data infrastructures of the geoinformation and library community is possible.

In addition, ICT-related resources for project coordination, internal communication and workflow management, such as Microsoft Sharepoint and mailing lists are available.

\subsection{Data sets and data modelling}

The InternetGIS kvwmap retrieves data, both from a local PostGIS spatial database system as well as from external data services (according to the OGC-based standards such as Web Feature Service and Web Map Service (WFS / WMS)). At this time data offered include around 30 layers (see Figure 4) of own basic data sets as well as special thematic data, historical maps. Furtheron 12 environmental thematic layers are embedded via WMS / WFS of the State Office for the Environment, Nature Conservation and Geology (LUNG) and LAIV MecklenburgVorpommern. Further resources are various historical data sources, such as the Digital Atlas of the Historic Mecklenburg on land use and settlement pattern in the 18th Century and census data for the Census in Mecklenburg-Schwerin in 1819 and 1867 (based on original cards) in the treatment.

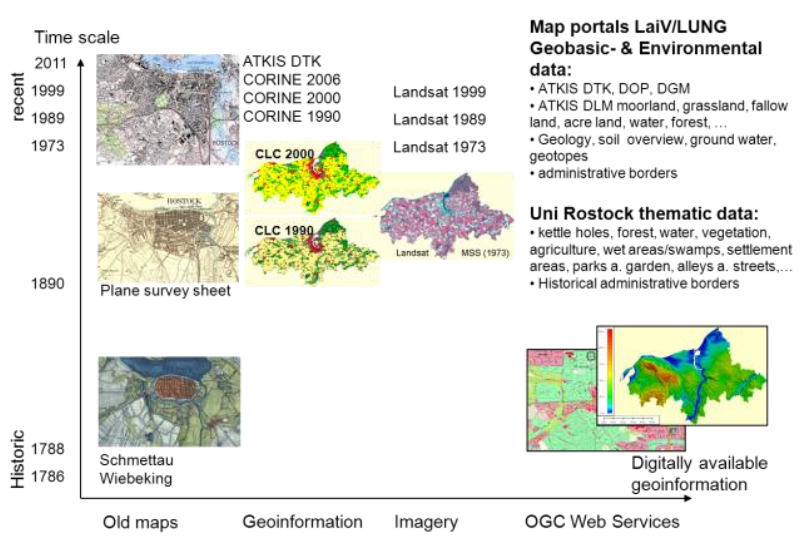

Figure 4. Used base maps and data sources.

The individual layers of the subject-specific research topics are based on more than 10 technical data models (Figure 5), which include for example attribute values on time section of the captured cards to the scientific information. To date, in research and student projects over 120,000 categories of spatial objects are digitized. More than 50 users are using VKLandLab for their research.

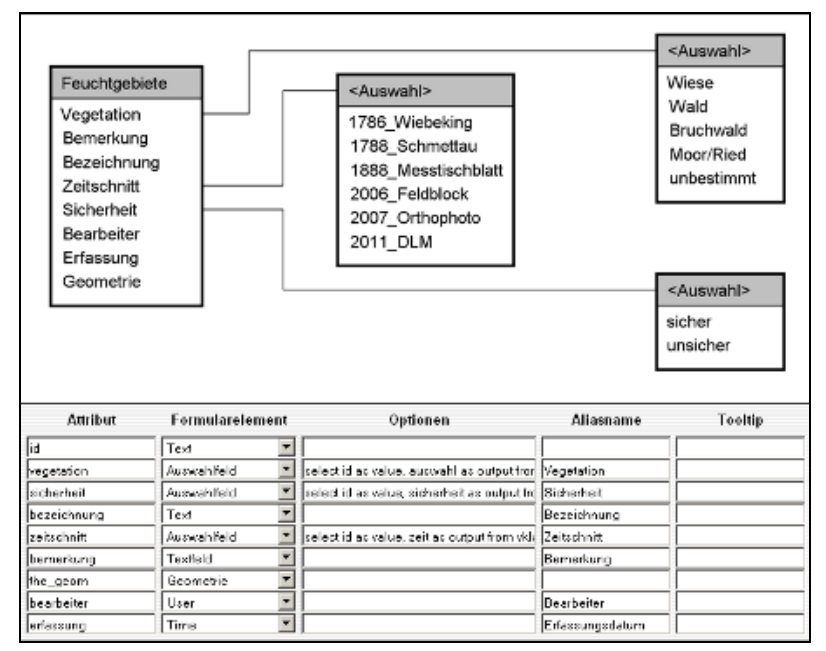

Figure 5. Thematic data model for swamp areas.

\section{RESEARCH CASE STUDIES}

\subsection{Master students research projects}

The virtual research platform was used in master student teaching and student training activities in the winter term in the module "Geoinformatics" in the specialisation "Integrated local planning" (Figure 6). Each student had to digitize a tile size of $10 * 10$ kilometers in Mecklenburg. Different objects, such as the settlement area, the wetlands, vegetation and agricultural use for the 3 time slices were captured within the virtual research laboratory and the InternetGIS kvwmap. Following this, a summary evaluation was done for each object class, and the results are displayed by using visualizations in form of maps and diagrams. Therefore the students used ArcGIS and Excel, in most cases by terminal server at their student apartment. 


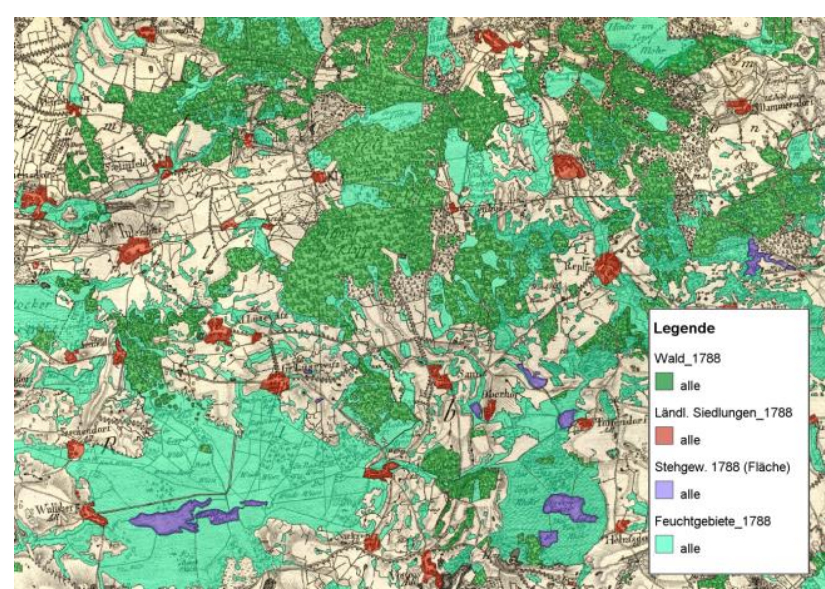

Figure 6: Captured forests, settlement and water areas within the time slice 1788 .

In addition each student had to solve an individual research question given by the above mentioned research disciplines. For instance students dealing with kettle holes had to investigate the place of the kettle hole in relation to the digital terrain model (DTM). Attributes such as slope and aspect had to be generated from DTM and appended to the attribute table for the kettle holes. Thus the student could analyse whether the kettle hole lies in the slope or in the plane, in the sink or on a summit.

Other students used different landscape metrics measures (such as nearest neigbor, shape index, proximity index) to derive information on the functioning and the interaction of the individual digitized objects.

Beside a lot of problems caused by the parallelism of developing the platform while students digitized, different versions of ArcGIS in the computer laboratory and via terminal server the students evaluated the use of the Internet platform in general as positive.

\subsection{Selected results in different research disciplines}

Landscape ecologists are interested in the distribution of forest zones over the last 230 years (Figure 7). Looking at the surface distribution of forest areas, on the one hand an increase in existing areas can be seen. Secondly the establishment of additional small patches can be recognized.

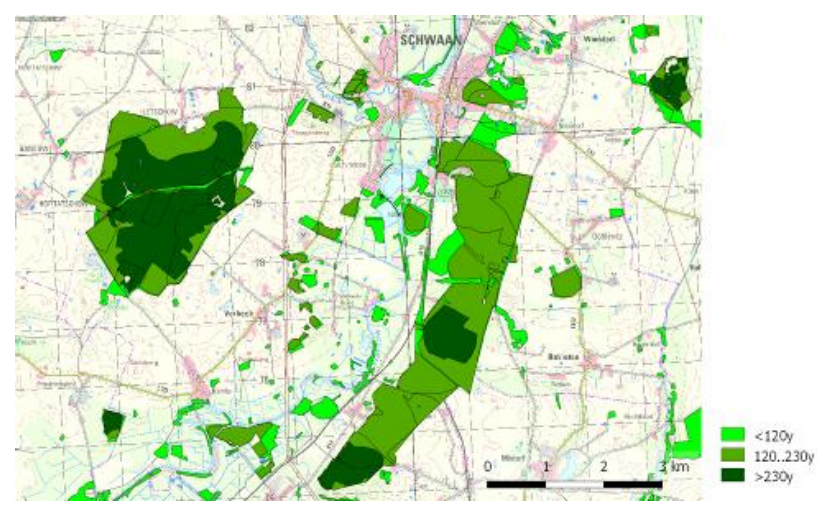

Figure 7. Forest zones in different age classes.

Geodesists were able to illustrate the high dynamics in kettle holes based on a regular raster of the size $5 * 5 \mathrm{~km}$ (Figure 8).

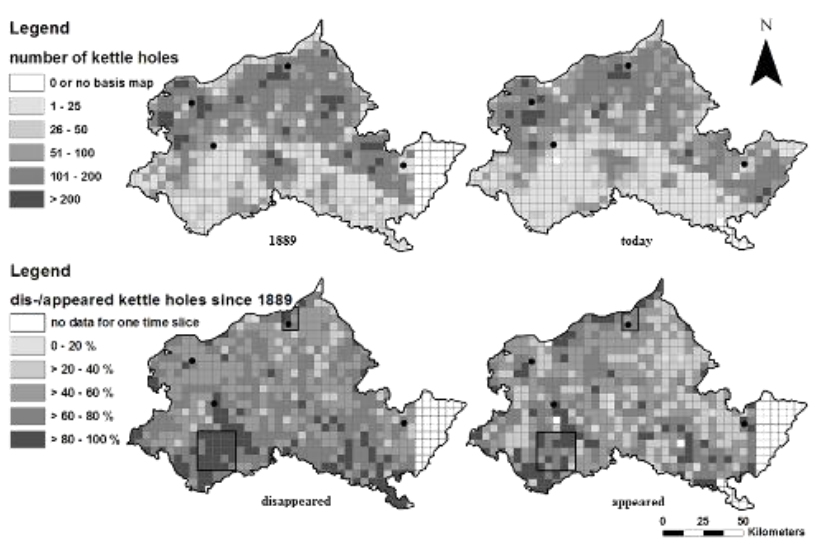

Figure 8. Number of kettle-holes and their dynamics since 1889 until today.

Figure 9 illustrates the different water courses for a part of the river Recknitz since 1786. The river length decreased for originally $71 \mathrm{~km}$ to nowadays only $55 \mathrm{~km}$, an important information for hydrologists for renaturation and water quality questions.

Simple queries allow all disciplines to derive standardized information at various levels (see Figure 10 at municipality level).

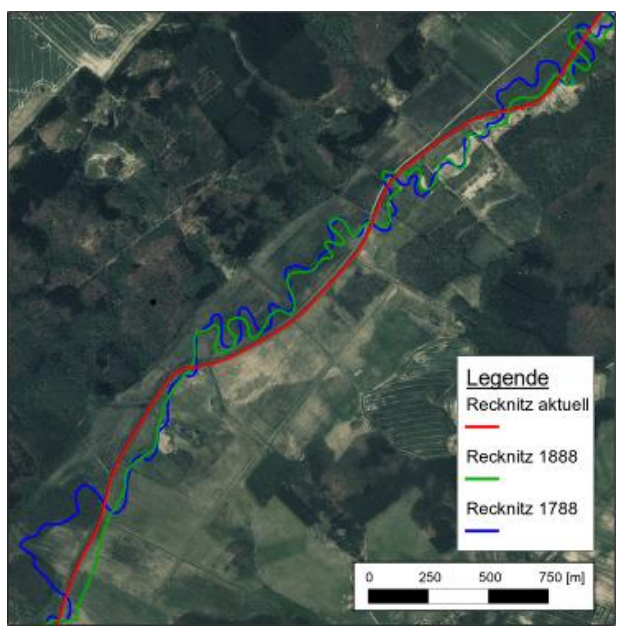

Figure 9. Water course changes of the river Recknitz. 


\begin{tabular}{|c|c|c|}
\hline \multicolumn{3}{|c|}{ Gemeinden } \\
\hline \multicolumn{2}{|c|}{$\Gamma$ Datensatz auswählen } & 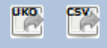 \\
\hline gid & 878 & \\
\hline gem_id_neu & 13060001 & \\
\hline gem_id_alt & 13033020 & \\
\hline Gemeinde & Banzkow & \\
\hline groesse_kl & 5 & \\
\hline amt_id & 11 & \\
\hline Amt & Amt Banzkow & \\
\hline Amtssitz & (Banzkow) & \\
\hline Kreis & Parchim & \\
\hline \multirow{3}{*}{ Vegetation 1788} & $0.23 \%$ Wiese/Grünland & \\
\hline & 43.00\% Moor/Sumpf/Ried & \\
\hline & $14.82 \%$ Wald & \\
\hline जासु & - Kartenausschnitt selektieren $\Gamma$ & \\
\hline
\end{tabular}

Figure 10. Vegetation area 1788 in the communities layer.

\section{CONCLUSION}

Virtual research environments will become available in many scientific disciplines. Beside some common shared technologies and components they always will have subject-specific characteristics. In the context of space- and time-related disciplines these are especially maps and geographic information systems. Hence the focus of VKLandLab lies on making available the existing comprehensive maps and geographical information in an Internet-based GIS, so that the special science dicisplines can already perform most of their collection and evaluation work within the virtual platform. Specialized analyzes are allowed via interfaces and interchange formats to common products such as ArcGIS, R or Excel.

\section{REFERENCES}

BILL, R. (2010): Grundlagen der Geo-Informationssysteme. Wichmann Verlag, Offenbach. 5. Auflage. 814 Seiten.

BILL, R., KORDUAN, P., RAHN, S. (2008): kvwmap - GISEntwicklung für Kommunen und Landkreise. In: Transfer, Das Steinbeis Magazin. Nr. 02, Seite 10-11.

BUSCH, M., KROLL, S., OLESEN, J.E., SCHOEBEL, M., ZÖLITZ, R. [HRSG.] (2011): Die schwedische Landesaufnahme von Pommern 1692-1709 - Perspektiven eines Editionsprojekts. Beiträge des Workshops am 9. und 10. Oktober 2009 im Pommerschen Landesmuseum Greifswald. Verlag Ludwig, Kiel, 200 S.

CARUSI, A., REIMER, T. (2010): Virtual Collaborative Landscape Study. A JISC funded project. (http://www.jisc.ac.uk/whatwedo/programmes/vre.aspx)

GREGORY, I.N., ELL, P.S. (2007): Historical GIS: Techniques, methodologies and scholarship. Cambridge University Press: Cambridge.

GROßE, B., ZINNDORF, S. (2001): Möglichkeiten und Grenzen der Nutzung von Altkarten, mobiler Scan-Technik und GIS-Anwendungen in der Landschaftsforschung. In: Scharfe, W. (Hrsg.): 10. Kartographiehistorisches Colloquium. Bonn 2000.
GROßE, B. (2003): Bedeutung digitaler Altkarten für GISAnwendungen in der Landschaftsforschung. Jahrestagung der Kartenkuratoren (D, CH), 26.5.2003, Freiburg.

KNOWLES, A.K. (2008, ED.): Placing History: How GIS is changing historical scholarship. ESRI Press: Redlands CA. Digital supplement edited by A. Hillier.

MOL, J.A., EKAMPER, P. (2010): De kadastrale kapstok: HISGIS Fryslân als model voor een Nederlands basissysteem. In: Boonstra, O. \& Schuurman, A. (Eds.), Tijd en ruimte: nieuwe toepassingen van GIS in de alfawetenschappen, pp. 198209. Utrecht

NEUBERT, M., WALZ, U. (2002): Auswertung historischer Kartenwerke für ein Landschaftsmonitoring. In: Strobl, J., Blaschke, T., Griesebner, G. (Hrsg.): Angewandte Geographische Informationsverarbeitung. XIV Beträge zum AGIT-Symposium Salzburg. Wichmann Verlag. Seite 396-402.

KREßNER, L. (2009): Digitale Analyse der Genauigkeit sowie der Erfassungs- und Darstellungsqualität von Altkarten aus Mecklenburg-Vorpommern - dargestellt an den Kartenwerken von Wiebeking (ca. 1786) und Schmettau (ca. 1788). Dissertation Universität Rostock.

PLÖGER, R. (2003): Inventarisierung der Kulturlandschaft mit Hilfe von Geographischen Informationssystemen (GIS). Methodische Untersuchung für historisch-geographische Forschungsaufgaben. Dissertation Rheinische FriedrichWilhelms-Universität Bonn.

WALZ, U., LUTZE, G., SCHULTZ, A., SYRBE, R.U. (2004, HRSG.): Landschaftsstruktur im Kontext von naturräumlicher Vorprägung und Nutzung - Datengrundlagen, Methoden und Anwendungen. IÖR-Schriften, Dresden. Band 43. 333 Seiten.

\section{Acknowledgements}

The author thanks the Deutsche Forschungsgemeinschaft (DFG) for funding the project within the funding virtual research laboratories programme (support code Bi 467/21-1). Further thanks go to all collaborators in this research project. 